\title{
Genipin Inhibits IL-1 $\beta$-Induced CCL20 and IL-6 Production from Human Periodontal Ligament Cells
}

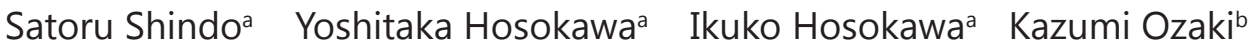 \\ Takashi Matsuo
}

Department of a Conservative Dentistry and Institute of Health Biosciences, The University of Tokushima Graduate School, and bDepartment of Oral Health Care Promotion, School of Oral Health and Welfare, Faculty of Dentistry, The University of Tokushima, Tokushima, Japan

\section{Key Words}

Genipin • IL-6 6 CCL20 • NF-KB • MAPKs • Periodontal ligament cells

\begin{abstract}
Background/Aims: Genipin, the aglycon of geniposide found in gardenia fruit has long been considered for treatment of various diseases in traditional oriental medicine. Genipin has been used as a blue colorant in food industry. Genipin has recently been reported to have some pharmacological functions, such as antimicrobial, antitumor, and anti-inflammatory effects. The aim of this study was to examine whether genipin could modify CCL20 and IL-6, which are related to bone resorption in periodontal disease, expression in human periodontal ligament cells (HPDLCs). Methods: CCL20 and IL- 6 productions from HPDLCs were determined by ELISA. Western blot analysis was used for the detection of signal transduction molecules expressions in HPDLCs. Results: Genipin prevented IL-1 $\beta$-mediated CCL20 and IL- 6 production in HPDLCs. Moreover, genipin could suppress nuclear factor kappa B (NF- $\kappa B)$ p65, extracellular signalregulated kinase (ERK) and MAPK/ERK kinase (MEK) phosphorylations in IL-1 $\beta$-stimulated HPDLCs. NF- $\kappa B$ inhibitor and ERK inhibitor significantly inhibited IL- 6 and CCL20 productions from IL-1 $\beta$-stimulated HPDLCs. Conclusions: These data provide a novel mechanism through which genipin could be used to provide direct benefits in periodontal disease to inhibit IL-6 and CCL20 productions in periodontal lesions.
\end{abstract}

Copyright (c) 2014 S. Karger AG, Basel

Dr. Yoshitaka Hosokawa
Department of Conservative Dentistry, Institute of Health Biosciences,

The University of Tokushima Graduate School, 3-18-15 Kuramoto-cho, Tokushima, Tokushima 770-8504 (Japan)

Tel. +81-886-33-7340, Fax +81-886-33-7340, E-Mail hosokawa@tokushima-u.ac.jp 


\section{Introduction}

Periodontitis is a chronic bacterial infection of tooth-supporting structures. It causes destruction of periodontal connective tissues and alveolar bone. The initiation and progression of the disease result from the host response to bacteria in biofilms. Previous studies have revealed many inflammatory immune cells infiltration, involving $\mathrm{T}$ cells, $\mathrm{B}$ cells and macrophages in periodontal legion [1-3]. Recently, a new type of T cell, Th17 cells, has been related with the pathogenesis of several inflammatory diseases [4]. Adibrad et al. recently demonstrated that a significant increase in the number of some specific markers of Th17 cells in patients suffering from periodontal disease in comparison with normal control subjects [5]. It is certain that Th17 could release high amount of IL-17A which is related to inflammatory bone resorption [6], and IL-17A levels in inflamed periodontal tissues are higher than those in healthy control tissues [7]. CCL20 is a CC chemokine which is related to Th17 cells migration and accumulation in inflammatory lesions [8]. We previously reported that CCL20 is expressed in periodontally disease tissues, and human gingival fibroblast could produce CCL20 [9]. Therefore, we would like to find some factors which could inhibit CCL20 production in periodontal lesion to decrease Th17 cells accumulation.

Interleukin-6 (IL-6) is an important cytokine involved in a number of physiologic and pathologic processes including response to infection and development and progression of inflammation [10]. It is produced from a variety of cells, such as fibroblasts, osteoblasts and vascular endothelial cells in inflammatory tissues [11-13]. IL-6 levels in gingival crevicular fluid samples are significantly correlated with probing depth and bleeding indices and furthermore with sites which showed further attachment loss during periodontal therapy compared to healthy sites [14]. It is known that IL-6 is involved in bone destruction in inflammatory lesions to activate osteoclasts because IL- 6 could induce RANKL expression in cells near osteoclasts [15]. Moreover, it is known that IL-6 is related to Th17 cells differentiation [16]. Therefore, we think IL-6 might be a therapeutic target of periodontal disease.

The fruit of Gardenia jasminoides Ellis is a medicinal herb that has been used for the treatment of inflammation, jaundice, and hepatic disorders. Genipin is the aglycon of geniposide found in gardenia fruit [17]. Genipin is a natural blue colorant in food industry. Genipin possesses a variety of pharmacological activities, such as hepatoprotective, and neurotrophic effects $[18,19]$ Recently, some researchers reported genpin has antiinflammatory effects. Nam et al. reported that genipin was effective at inhibiting LPS-induced nitric oxide (NO) release from cultured rat brain microglial cells [20]. Li et al. reported that genipin had anti-inflammatory effects in a model of LPS-induced acute systemic inflammation via downregulation of IL-1 $\beta$ and TNF- $\alpha$ productions [21]. However the effect of genipin on Th17 cells related proteins, such as CCL2 0 and IL-6, productions is unknown.

The aim of this study was to examine the effect of genipin on CCL20 and IL-6 productions from IL-1 $\beta$-stimulated human periodontal ligament cells (HPDLCs) which is a major cell in periodontal tissues. Moreover, we investigated whether genipin treatment modified the

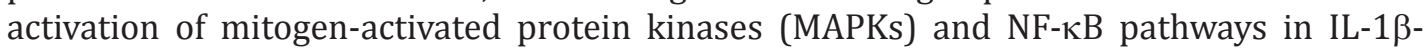
stimulated HPDLCs.

\section{Materials and Methods}

\section{Cell culture}

Human periodontal ligament cells (HPDLCs) were obtained from TaKaRa Biotechnology Co., Ltd. (Otsu, Shiga, Japan) and grown in the Dulbecco's modified Eagle medium (DMEM: Sigma, St. Louis, MO, USA) supplemented with 10\% fetal bovine serum (FBS: Gibco, Grand Island, NY, USA) and antibiotics (penicillin G: 100 units $/ \mathrm{ml}$, streptomycin: $100 \mu \mathrm{g} / \mathrm{ml}$ ) at $37^{\circ} \mathrm{C}$ in humidified air with $5 \% \mathrm{CO}_{2}$. Cells were used between passage numbers 5 and 10. 


\section{CCL20 and IL-6 production in HPDLCS}

The HPDLCs were stimulated with recombinant human IL-1 $\beta$ (Peprotech, Rocky Hill, NJ, USA) for 24 hours. The supernatants from the HPDLCs were collected, and the CCL20 and IL- 6 concentrations of the culture supernatants were measured in triplicate with ELISA. Duoset (R\&D systems, Minneapolis, MN, USA) was used for the determination. All assays were performed according to the manufacturer's instructions, and cytokine levels were determined using the standard curve prepared for each assay. In selected experiments, the HPDLCs were cultured for 1 hour in the presence or absence of Genipin $(3.125,6.25,12.5$,or $25 \mu \mathrm{g} / \mathrm{ml}$ : Cayman Chemical, Ann Arbor, MI, USA) ,SB203580 (10 $\mu$ M: Santa Cruz Biotechnology, Santa Cruz, CA, USA),

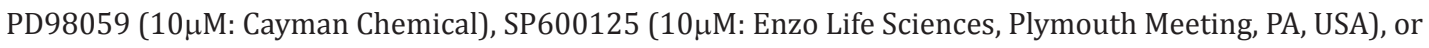

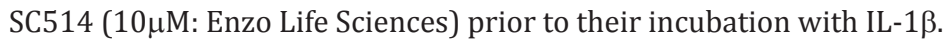

\section{Western blot analysis}

To confirm the IL-1 $\beta$-induced phosphorylation of signal transduction molecules, western blot analysis was performed. HPDLCs stimulated by IL- $1 \beta(10 \mathrm{ng} / \mathrm{ml})$ with or without genipin $(12.5 \mathrm{or} 25 \mu \mathrm{g} /$ $\mathrm{ml}$ ) pretreatment for 1 hour were washed once with cold PBS, before being incubated on ice for $30 \mathrm{~min}$ with cell lysis buffer (Cell signaling technology, Danvers, MA, USA) supplemented with protease inhibitors cocktail (Sigma). After removal of debris by centrifugation, the protein concentrations of the lysates were quantified with the Bradford protein assay using IgG as a standard. A $20 \mu \mathrm{g}$ protein sample was loaded onto a 4-20\% SDS-PAGE gel, before being electrotransfered to a PVDF membrane. The phosphorylation of NF- $\mathrm{kB}$ p65, p38 MAPK, ERK, JNK, and MEK or the degradation of IKB- $\alpha$ was assessed using phospho-NF-kB p65 rabbit monoclonal antibody (Cell signaling technology), phospho-p38 MAPK rabbit monoclonal antibody (Cell signaling technology), phospho-ERK rabbit monoclonal antibody (Cell signaling technology), phosphoJNK rabbit monoclonal antibody (Cell signaling Technology), phospho-MEK rabbit monoclonal antibody (Cell signaling Technology), NF-kB p65 rabbit monoclonal antibody (Cell signaling technology), p38 MAPK rabbit monoclonal antibody (Cell signaling technology), ERK rabbit monoclonal antibody (Cell signaling Technology), JNK rabbit monoclonal antibody (Cell Signaling Technology), MEK rabbit monoclonal antibody (Cell signaling technology), IкB- $\alpha$ mouse monoclonal antibody (Cell signaling antibody), or GAPDH rabbit monoclonal antibody (Cell signaling technology) according to the manufacturer's instructions. Protein bands were visualized by incubation with the HRP-conjugated secondary antibody (Sigma), followed by detection using the ECL system (GE Healthcare, Uppsala, Sweden). The quantitation of the chemiluminescent signal was analyzed using ImageJ (version 1.44).

Statistical analysis

Statistical significance was analyzed using the Student's $t$ test. $P$ values $<0.05$ were considered significant in Fig. 1 and 2.

\section{Results}

The effect of IL-1 $1 \beta$ on CCL20 or IL-6 productions from HPDLCs.

We first investigated whether IL-1 $\beta$ was able to induce CCL20 or IL- 6 productions in HPDLCs because there is no report that explained whether IL-1 $\beta$ stimulation could induce CCL20 production in HPDLCs. As shown in Fig. 1, IL-1 $\beta$ could increase both CCL20 and IL-6 productions in HPDLCs.

Effects of genipin on CCL20 and IL-6 productions in IL-1 $\beta$-stimulated HPDLCS

To investigate the effects of genipin on IL-1 $\beta$-induced CCL20 and IL- 6 production, HPDLCs were pretreated with genipin at the indicated concentrations for 1 hour and stimulated with IL-1 $\beta$ for 24 hours. Treatment with 12.5 or $25 \mu \mathrm{g} / \mathrm{ml}$ of genipin significantly inhibited CCL2 0 production in IL-1 $\beta$-stimulated HPDLCs (Fig. 1A). IL-6 production from IL$1 \beta$-treated HPDLCs was decreased by $6.25,12.5$ or $25 \mathrm{mg} / \mathrm{ml}$ genipin pretreatment (Fig. 1B). 


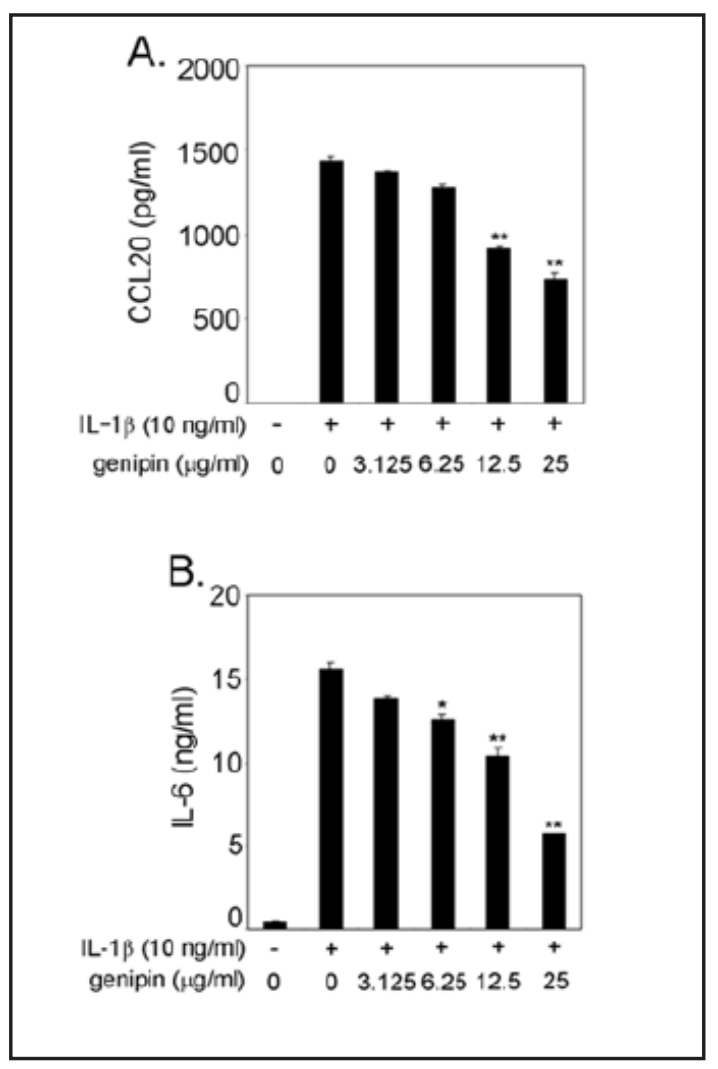

Fig. 1. Effects of genipin on CCL20 and IL-6 production in IL-1 $\beta$-stimulated HPDLCs. HPDLCs were pretreated with genipin $(3.125,6.25,12.5$, or $25 \mu \mathrm{g} /$ $\mathrm{ml}$ ) for 1 hour, and then the HPDLCs were stimulated with IL-1 $\beta(10 \mathrm{ng} / \mathrm{ml})$, and the supernatants were collected after 24 hours. The expression levels of CCL20 (A) and IL-6 (B) in the supernatants were measured using ELISA. The results are shown as the mean and SD of one representative experiment performed in triplicate. The error bars show the SD of the values. ${ }^{*}=P<0.05,{ }^{* *}=P<0.01$ significantly different from the IL-1 $\beta$-stimulated HPDLCs without catechins.

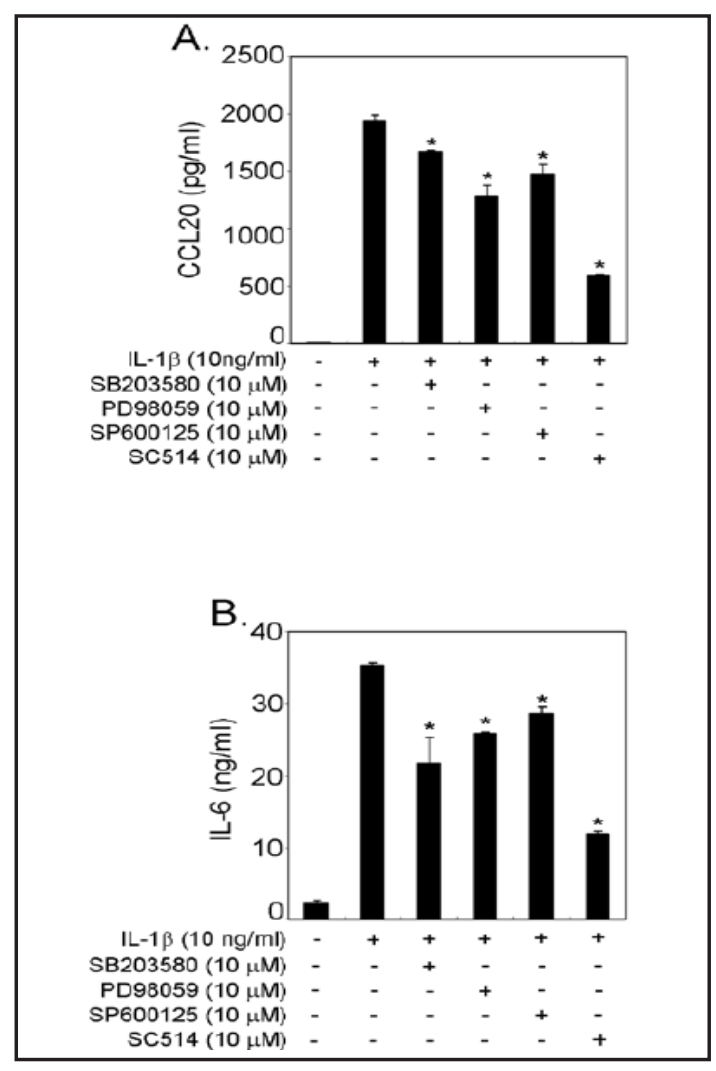

Fig. 2. Effects of signal transduction inhibitors on IL-1 $\beta$-stimulated CCL20 and IL- 6 release by HPDLCs. The cells were pre-incubated with SB203580 (10 $\mu \mathrm{M})$, PD98059 $(10 \mu \mathrm{M}), \operatorname{SP} 600125(10 \mu \mathrm{M})$, or SC514 $(10 \mu \mathrm{M})$ for 1 hour and then incubated with IL-1 $\beta$ (10 ng/ml). After 24 hours incubation, the supernatants were collected, and CCL20 (A) and IL-6 (B) productions were measured by ELISA. The results are shown as the mean and SD of one representative experiment performed in triplicate. The error bars show the SD of the values. ${ }^{*}=P<0.01$ significantly different from the IL-1 $\beta$-stimulated HPDLCs without inhibitors.

$N F-\kappa B$ and MAPKs pathways are related to CCL20 or IL-6 productions in IL-1 $\beta$-stimulated HPDLCS

We previously reported that MAPKs and NF- $\kappa B$ pathways are involved in CCL20 or IL-6 productions in HGFs [22]. Therefore, we examined the effects of MAPKs and NF- $\kappa B$ inhibitors on CCL20 or IL- 6 productions in IL-1 $\beta$-stimulated HPDLCs. Fig. 2 shows that a p38 MAPK inhibitor (SB203580), an ERK inhibitor (PD98059), a JNK inhibitor (SP600125), or a NF- $\kappa B$ inhibitor (SC514) significantly suppressed CCL20 or IL-6 productions in IL-1 $\beta$ stimulated HPDLCs.

Effects of genipin on $N F-\kappa B$ p65 phosphorylation and I $\mathrm{K} B-\alpha$ degradation in $I L-1 \beta$ stimulated HPDLCS

Next, we examined the effects of genipin on the NF- $\kappa B$ pathway activation in IL-1 $\beta$ stimulated HPDLCs because it is reported that IL-1 $\beta$ could activate the NF- $\kappa B$ pathway in HPDLCs [23]. Fig. 3 shows that IL-1 $\beta$ stimulation induced NF- $\kappa B$ p65 phosphorylation and 


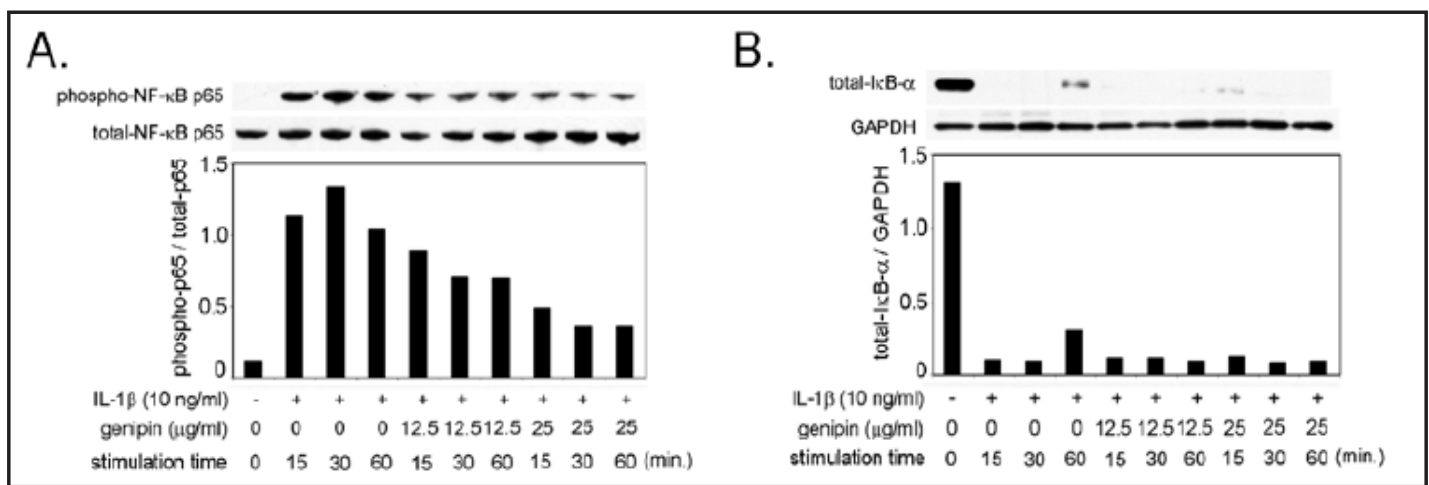

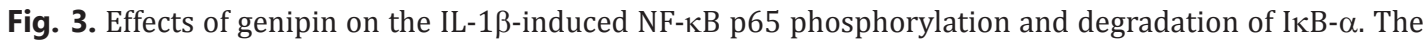
cultured cells were pretreated with genipin (12.5 or $25 \mu \mathrm{g} / \mathrm{ml}$ ) for $60 \mathrm{~min}$ and then stimulated with 10ng/ $\mathrm{ml}$ IL-1 $\beta$ for 15,30 , or $60 \mathrm{~min}$. The cell extracts were subjected to SDS-PAGE followed by. The phosphorylati-

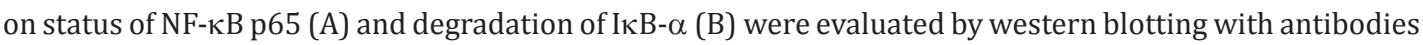
as described in Materials and Methods. A representative western blot displaying phospho-NF- $\kappa \mathrm{B}$ p65, total-

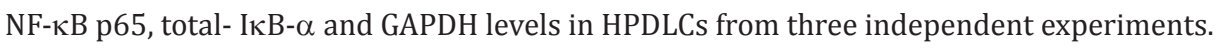

Fig. 4. Effects of genipin on the IL-1 $\beta$-induced phosphoylations of p38 MAPK, ERK, and JNK. The cultured cells were pretreated with genipin (12.5 or 25 $\mu \mathrm{g} / \mathrm{ml}$ ) for $60 \mathrm{~min}$ and then stimulated with $10 \mathrm{ng} /$ $\mathrm{ml}$ IL-1 $\beta$ for 15,30 , or $60 \mathrm{~min}$. The cell extracts were subjected to SDS-PAGE followed by. The phosphorylation status of p38 MAPK (A), ERK (B), and JNK (C) was evaluated by western blotting with antibodies as described in Materials and Methods. A representative western blot displaying phospho-p38 MAPK, total-p38 MAPK, phospho-ERK, total-ERK, phospho-JNK, and total-JNK levels in HPDLCs from three independent experiments.

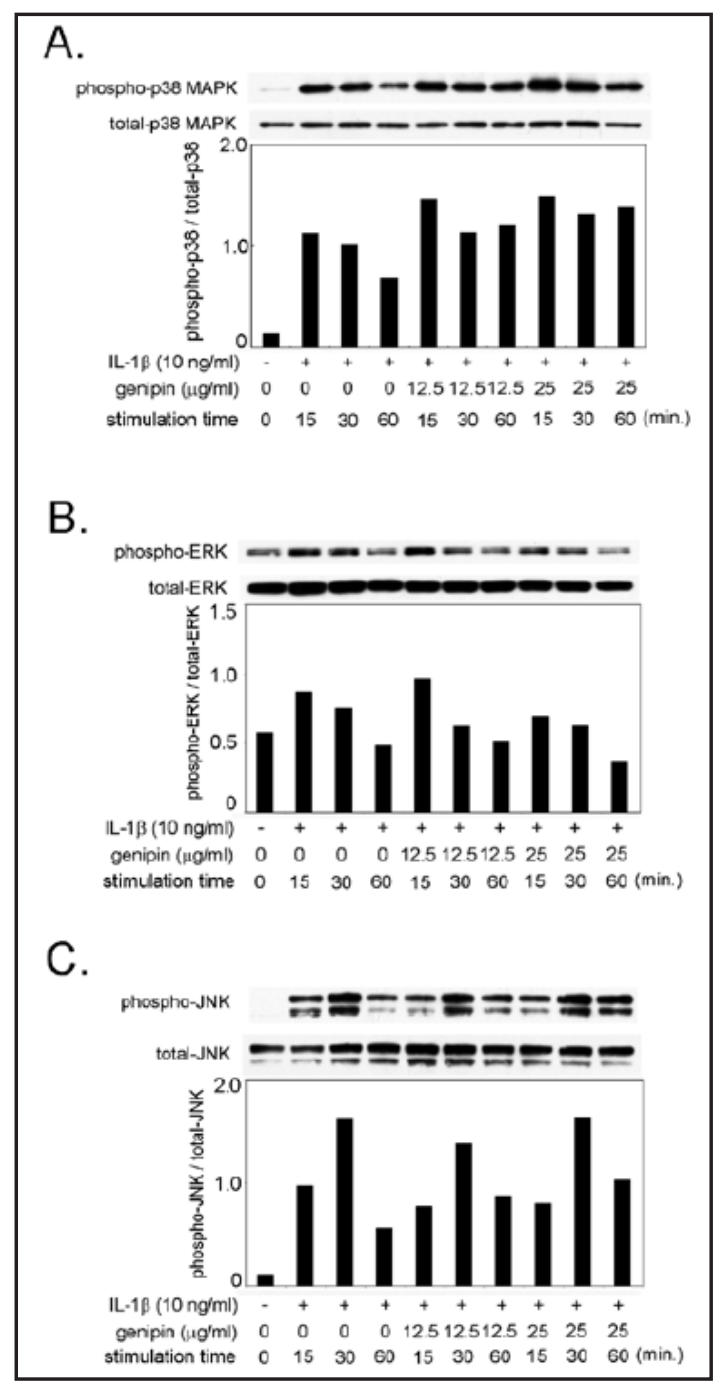

I $\kappa$ B- $\alpha$ degradation. Genipin treatment inhibited NF- $\kappa$ B p 65 phosphorylation though genipin did not modulate IкB- $\alpha$ degradation in IL-1 $\beta$-stimulated HPDLCs. 
Fig. 5. Effects of genipin on the IL-1 $\beta$-induced phosphoylations of MEK. The cultured cells were pretreated with genipin (12.5 or $25 \mu \mathrm{g} / \mathrm{ml}$ ) for $60 \mathrm{~min}$ and then stimulated with $10 \mathrm{ng} / \mathrm{ml} \mathrm{IL-} 1 \beta$ for 15,30 , or $60 \mathrm{~min}$. The cell extracts were subjected to SDS-PAGE followed by. The phosphorylation status of MEK was evaluated by western blotting with antibodies as described in Materials and Methods. A representative western blot displaying phospho-MEK, and total-MEK levels in HPDLCs from three independent experiments.

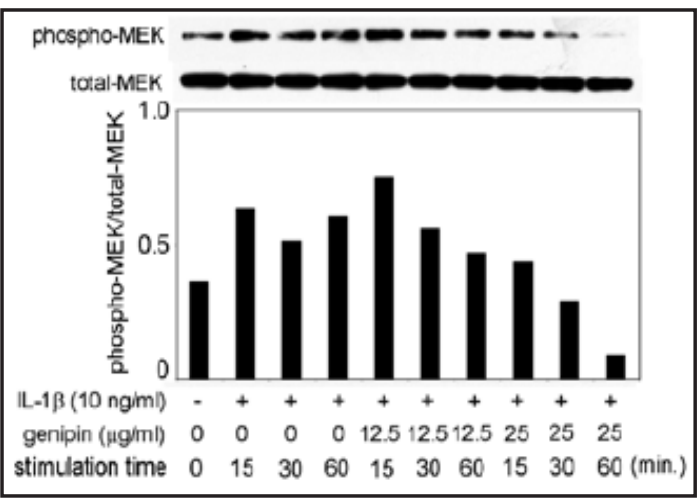

Effects of genipin on MAPKs activations in IL-1 $\beta$-stimulated HPDLCs

Next, we examined the effects of genipin on MAPKs phosphorylation in IL-1 $\beta$-stimulated HPDLCs because MAPKs inhibitor could suppress CCL20 and IL-6 production in Fig. 2. Fig. 4 shows that IL-1 $\beta$ stimulation induced the phosphorylations of p38 MAPK, ERK and JNK in HPDLCs. Genipin treatment apparently suppressed ERK phosphorylation in IL-1 $\beta$-stimulated HPDLCs though p38 MAPK and JNK phosphorylations were not suppressed.

Effect of genipin treatment on MEK phosphorylation in IL-1 $\beta$-treated HPDLCS

Finally, we investigated the MEK phosphorylation because MEK is the upstream kinase of ERK. Fig. 5 shows that genipin treatment apparently suppressed MEK phosphorylation in IL-1 $\beta$-stimulated HPDLCs. Therefore, Fig. 4 and Fig. 5 explain that genipin could inhibit the MEK/ERK pathway in IL-1 $\beta$-stimulated HPDLCs.

\section{Discussion}

In this study, we demonstrated, for the first time to our knowledge, that genipin could suppress CCL20 and IL-6 productions from IL-1 $\beta$-stimulated HPDLCs. Some researchers demonstrated that genipin could inhibit inflammatory mediator productions from some kinds of cells. Nam et al. reported that genipin treatment inhibited IL-1 $\beta$ and TNF- $\alpha$ production from LPS-stimulated rat brain microglia cells [20]. Wang et al. reported that blue pigment derived from genipin could suppress TNF- $\alpha$ and IL-6 productions from LPS-stimulated RAW 264.7 murine macrophages cell line [24]. Hwa et al. reported that genipin could suppress VCAM-1 expression on TNF- $\alpha$-stimulated human endothelial cells [25]. Their reports and our report revealed that genipin could inhibit some kinds of inflammatory factors, including cytokines and adhesion molecules, expressions in inflammatory lesions. We should examine the effects of genipin on various cells in periodontal tissues, such as gingival epithelial cells and gingival fibroblasts, because genipin could contact with these cells as well as HPDLCs when we apply genipin in periodontal pockets for treatment of periodontal disease.

Some researchers examined the effect of genipin on NF- $\kappa$ B activations because NF$\kappa \mathrm{B}$ is important for controlling the expression of many proinflammatory factors and has been recognized as an important drug target for the treatment of inflammatory diseases. Previous reports demonstrated that genipin treatment could inhibit NF- $\mathrm{KB}$ activation in LPS-stimulated cells $[21,24]$. It is known that IL-1 $\beta$ stimulation could induce the NF- $\mathrm{KB}$ pathway activation in HPDLCs [23]. Therefore, we examined the effects of genipin on NF$\kappa \mathrm{B}$ p65 phosphorylation and I $\kappa \mathrm{B}-\alpha$ degradation to clarify the NF- $\kappa \mathrm{B}$ activation. Our results demonstrated that genipin suppressed NF- $\kappa B$ p65 phosphorylation though did not change I $\kappa \mathrm{B}-\alpha$ degradation in IL-1 $\beta$-stimulated HPDLCs. It is reported that apigenin, a flavonoid found in fruits and vegetables, did not change degradation of IкB- $\alpha$ in LPS-stimulated primary human monocytes. On the other hand, the same authors reported that apigenin suppressed NF- $\kappa$ B p65 phosphorylation in LPS-treated mouse macrophages [26]. Results of the report are similar with our results in this manuscript. 
There are some reports that examined the effects of genipin on the phosphorylation of MAPKs. For example, genipin could enhance p38 MAPK and JNK phosphorylation, and induce apoptosis of breast cancer cells [27]. However, there were few reports that demonstrated the effect of genipin on activations of MAPKs in normal cells as far as we know. It is known that IL-1 $\beta$ could induce p38 MAPK, ERK, and JNK phosphorylations in HPDLCs [23]. Therefore, we investigated the effect of genipin on these 3 MAPKs pathways. We revealed that genipin treatment could inhibit the MEK/ERK pathway activation in IL-1 $\beta$-stimulated HPDLCs. It is known that the MEK/ERK pathway activation is related to some inflammatory mediator expressions in HPDLCs $[28,29]$. Therefore, we will examine the effects of genipin on ERK activation-related molecules except CCL20 and IL-6.

In summary, the current study demonstrates that genipin could suppress IL- $1 \beta$-induced CCL20 and IL-6 production in HPDLCs. In addition, we revealed that genipin inhibited IL-1 $\beta$ induced MEK/ERK pathway activation in HPDLCs. We think that the direct effects of genipin inhibit CCL2 0 and IL-6 production in IL-1 $\beta$-stimulated HPDLCs in order to inhibit the phosphorylation of signal transduction molecules. These data provide a novel mechanism through which genipin could be used to provide periodontal benefits in periodontal disease.

\section{Conflict of Interest}

The authors confirm that there are no conflicts of interest.

\section{Acknowledgements}

This study was supported by Grant-in-Aid for Young Scientists (23792479), Grant-inAid for Scientific Research (C) (25463219), and Grant-in-Aid for Scientific Research (B) (23390435) from the Ministry of Education, Culture, Sports, Science and Technology of Japan.

\section{References}

1 Seymour GJ: Importance of the host response in the periodontium. J Clin Periodontol 1991;18:421-426.

-2 Page RC, Offenbacher S, Schroeder HE, Seymour GJ, Kornman KS: Advances in the pathogenesis of periodontitis: summary of developments, clinical implications and future directions. Periodontol 2000 1997;14:216-248.

-3 Fujihashi K, Kono Y, Beagley KW, Yamamoto M, McGhee JR, Mestecky J, Kiyono H: Cytokines and periodontal disease: immunopathological role of interleukins for B cell responses in chronic inflamed gingival tissues. J Periodontol 1993;64:400-406.

-4 Afzali B, Lombardi G, Lechler RI, Lord GM: The role of T helper 17 (Th17) and regulatory T cells (Treg) in human organ transplantation and autoimmune disease. Clin Exp Immunol 2007;148:32-46.

-5 Adibrad M, Deyhimi P, Ganjalikhani Hakemi M, Behfarnia P, Shahabuei M, Rafiee L: Signs of the presence of Th17 cells in chronic periodontal disease. J Periodontal Res 2012;47:525-531.

-6 Joosten LA, Abdollahi-Roodsaz S, Heuvelmans-Jacobs M, Helsen MM, van den Bersselaar LA, OppersWalgreen B, Koenders MI, van den Berg WB: T cell dependence of chronic destructive murine arthritis induced by repeated local activation of Toll-like receptor-driven pathways: crucial role of both interleukin1beta and interleukin-17. Arthritis Rheum 2008;58:98-108.

7 Vernal R, Dutzan N, Chaparro A, Puente J, Antonieta Valenzuela M, Gamonal J: Levels of interleukin-17 in gingival crevicular fluid and in supernatants of cellular cultures of gingival tissue from patients with chronic periodontitis. J Clin Periodontol 2005;32:3 83-89.

- 8 Hirota K, Yoshitomi H, Hashimoto M, Maeda S, Teradaira S, Sugimoto N, Yamaguchi T, Nomura T, Ito H, Nakamura T, Sakaguchi N, Sakaguchi S: Preferential recruitment of CCR6-expressing Th17 cells to inflamed joints via CCL20 in rheumatoid arthritis and its animal model. J Exp Med 2007;204:2803-2812. 
Shindo et al.: Genipin Inhibits IL-6 and CCL20 Productions

-9 Hosokawa Y, Nakanishi T, Yamaguchi D, Takahashi K, Yumoto H, Ozaki K, Matsuo T: Macrophage inflammatory protein 3alpha-CC chemokine receptor 6 interactions play an important role in CD4+ T-cell accumulation in periodontal diseased tissue. Clin Exp Immunol 2002;128: 548-554.

10 Bendtzen K: Interleukin 1,interleukin 6 and tumor necrosis factor in infection, inflammation and immunity. Immunol Lett 1988;19: 183-191.

11 Bartold PM, Haynes DR: Interleukin-6 production by human gingival fibroblasts. J Periodontal Res 1991;26:339-345.

12 Ishimi Y, Miyaura C, Jin CH, Akatsu T, Abe E, Nakamura Y, Yamaguchi A, Yoshiki S, Matsuda T, Hirano T: IL-6 is produced by osteoblasts and induces bone resorption. J Immunol 1990;145:3297-3303.

- 13 Jirik FR, Podor TJ, Hirano T, Kishimoto T, Loskutoff DJ, Carson DA, Lotz M: Bacterial lipopolysaccharide and inflammatory mediators augment IL-6 secretion by humanendothelial cells. J Immunol 1989;142:144-147.

14 Geivelis M, Turner DW, Pederson ED, Lamberts BL: Measurements of interleukin-6 in gingival crevicular fluid from adults with destructive periodontal disease. J Periodontol 1993;64:980-983.

-15 Hashizume M, Hayakawa N, Mihara M: IL-6 trans-signalling directly induces RANKL on fibroblast-like synovial cells and is involved in RANKL induction by TNF-alpha and IL-17. Rheumatology 2008;47:16351640 .

- 16 Bettelli E, Carrier Y, Gao W, Korn T, Strom TB, Oukka M, Weiner HL, Kuchroo VK: Reciprocal developmental pathways for the generation of pathogenic effector TH17 and regulatory T cells. Nature 2006;441:235-238.

17 He ML, Cheng XW, Chen JK, Zhou TS: Simultaneous determination of five major biologically active ingredients in different parts of Gardenia jasminoides fruits by HPLC with diode-array detection. Chromatographia 2006;64:713-717.

- 18 Takeuchi S, Goto T, Mikami K, Miura K, Ohshima S, Yoneyama K, Sato M, Shibuya T, Watanabe D, Kataoka E, Segawa D, Endo A, Sato W, Yoshino R, Watanabe S: Genipin prevents fulminant hepatic failure resulting in reduction of lethality through the suppression of TNF-alpha production. Hepatol Res. 2005;33:298-305.

19 Yamazaki M, Chiba K: Genipin exhibits neurotrophic effects through a common signaling pathway in nitric oxide synthase-expressing cells. Eur J Pharmacol 2008;581:255-261.

-20 Nam KN, Choi YS, Jung HJ, Park GH, Park JM, Moon SK, Cho KH, Kang C, Kang I, Oh MS, Lee EH: Genipin inhibits the inflammatory response of rat brain microglial cells. Int Immunopharmacol 2010;10:493-499.

-21 Li CC, Hsiang CY, Lo HY, Pai FT, Wu SL, Ho TY: Genipin inhibits lipopolysaccharide-induced acute systemic inflammation in mice as evidenced by nuclear factor- $\kappa \mathrm{B}$ bioluminescent imaging-guided transcriptomic analysis. Food Chem Toxicol 2012;50:2978-2986.

-22 Hosokawa Y, Hosokawa I, Ozaki K, Nakae H, Matsuo T: Increase of CCL20 expression by human gingival fibroblasts upon stimulation with cytokines and bacterial endotoxin. Clin Exp Immunol 2005;142:285-291.

23 Murayama R, Kobayashi M, Takeshita A, Yasui T, Yamamoto M: MAPKs, activator protein-1 and nuclear factor$\kappa \mathrm{B}$ mediate production of interleukin-1 $\beta$-stimulated cytokines, prostaglandin $\mathrm{E}_{2}$ and MMP-1 in human periodontal ligament cells. J Periodontal Res 2011;46:568-575.

24 Wang QS, Xiang Y, Cui YL, Lin KM, Zhang XF: Dietary blue pigments derived from genipin, attenuate inflammation by inhibiting LPS-induced iNOS and COX-2 expression via the NF- $\kappa$ B inactivation. PLoS One 2012; 7:e34122.

-25 Hwa JS, Mun L, Kim HJ, Seo HG, Lee JH, Kwak JH, Lee DU, Chang KC: Genipin Selectively Inhibits TNF- $\alpha$ activated VCAM-1 But Not ICAM-1 Expression by Upregulation of PPAR- $\gamma$ in Human Endothelial Cells. Korean J Physiol Pharmacol 2011;15:157-162.

-26 Nicholas C, Batra S, Vargo MA, Voss OH, Gavrillin MA, Wewers MD, Guttridge DC, Groteword E, Doseff AI: Apigenin blocks lipopolysaccharide-induced lethality in vivo and proinflammatory cytokines expression by inactivating NF-kB through the supression of p65 phosphorylation. J Immunol 2007;179:7121-7127

27 Kim ES, Jeong CS, Moon A: Genipin, a constituent of Gardenia jasminoides Ellis, induces apoptosis and inhibits invasion in MDA-MB-231 breast cancer cells. Oncol Rep 2012;27:567-572.

28 Zhu L, Wu Y, Wei H, Yang S, Zhan N, Xing X, Peng B: Up-regulation of IL-23 p19 expression in human periodontal ligament fibroblasts by IL-1 $\beta$ via concurrent activation of the NF- $\kappa B$ and MAPKs/AP-1 pathways. Cytokine 2012;60:171-178.

-29 Guan SM, Zhang M, He JJ, Wu JZ: Mitogen-activated protein kinases and phosphatidylinositol 3-kinase are involved in Prevotella intermedia-induced proinflammatory cytokines expression in human periodontal ligament cells. Biochem Biophys Res Commun 2009;386:471-476. 